\title{
Historia de la enseñanza de la microbiología en Chile: centros formadores
}

\author{
Carlos Osorio
}

\section{Beginning of the Microbiology education in Chile: formation centers}

The first Chair of Microbiology in Chile was created in the School of Medicine of the Cañadilla at the University of Chile in 1892. Dr. Alejandro del Río Soto Aguilar was its first Professor. For almost three decades it was the only educational center for microbiologists in Chile. Among them were the first Professors of the new School of Medicine of the Catholic University of Chile and of the University of Concepción.

Key words: History of medicine, microbiology, Chile.

Palabras clave: Historia de la medicina, microbiología, Chile.

"Sic transit gloria mundi."

Imitación de Cristo

Tomás de Kempis

\section{Teoría de los gérmenes infecciosos en Chile}

$\mathrm{E}$ $n$ la década de 1890 en Europa ya estaba plenamente consolidada la moderna teoría de los gérmenes como agentes etiológicos de las enfermedades infecciosas. Esta teoría había iniciado su desarrollo a mediados del siglo XIX, principalmente con los trabajos del italiano Agustino Bassi (1773-1856), y luego con los experimentos del francés Louis Pasteur (1822-1895) y el alemán Robert Koch (1843-1910), sólo por nombrar a sus principales figuras. Deben destacarse los experimentos de Bassi durante la década de 1830, pues son bastante menos conocidos que los de sus insignes sucesores. El profesor Bassi pudo demostrar fehacientemente que un agente fúngico era el responsable de causar una enfermedad infecciosa en el gusano de la seda; específicamente el agente involucrado fue denominado en su honor Beauveria bassiana. En 1835 fue publicada su gran obra que sintetizaba su trabajo de cerca de veinte años, titulada: "Del mal del segno, calcinaccio o moscardino".

En Chile, la mayoría de los médicos a mediados del siglo XIX pensaba que las enfermedades infecciosas tenían un origen multicausal, siendo los agentes infecciosos sólo una de las causas dentro de una pléyade de posibilidades, tales como atmosféricas, telúricas, climáticas, factores del hospedero y otras (ozono, miasmas, etc.). Un interesante párrafo de don Teodoro Piderit en un ensayo presentado a la Facultad de Medicina en 1851 merece ser citado: "Algunos han supuesto un miasma animado del cólera, $i$ han opinado: que insectos tan menudos que no se podían descubrir aun con el microscopio sean la causa de la epidemia. Mientras que estos insectos no sean apreciados por nuestra vista, no podrá ocupar nuestra atención esta hipótesis"2. Es importante destacar que esta concepción del Dr. Piderit fue planteada antes de los famosos experimentos de Pasteur y Koch (de la segunda mitad del s. XIX) y que, al parecer, reflejaba una tradición milenaria en occidente, pues podemos encontrar una párrafo similar en la obra Rerum rusticarum de Agri Cultura del destacado polígrafo romano Marco Terencio Varrón (116-26 a.C.). Comentando Varrón sobre dónde idealmente se debería construir una villa, dice que hay que tener cautela con los lugares pantanosos porque: “...cuando se secan dichos terrenos, pequeñisimos animales que el ojo no puede observar, penetran en el cuerpo por la boca y la nariz."3. Otros célebres proponentes de que estos pequeños animales (animálculos) o insectos invisibles podían ser la causa de las enfermedades infecciosas fueron Girólamo Fracastoro, Athanasius Kirchner, Carolus Linnaeus y Benjamín Marten³.

En 1865 el destacado académico Dr. Valentín Saldías en su discurso de incorporación a la Universidad de Chile titulado "Causa de las epidemias" expresa lo siguiente: "Para el mayor número de ellas (las epidemias) es forzoso admitir al aire como vehículo y conductor, y si fuese verdad que en efecto existían suspendidas en él, ¿cómo se encuentran, de dónde vienen, cuál es su forma, hay algo de material, de invisible, de imponderable? Si son cuerpos materiales deben tener una forma, i raro seria que al enunciarlos no se les hubiera descrito con sus propiedades y caracteres." ${ }^{\text {. }}$. El mismo año, el Dr. Manuel Antonio Carmona en un informe médico-legal sobre una epidemia de viruela que asolaba Valparaíso, expresaba: "He dicho que el contagio en general es un humor o
Universidad de Chile, Santiago,

Chile.

Facultad de Medicina

Instituto de Ciencias Biomédicas

Programa de Microbiología y

Micología.

Recibido: 10 de abril de 2015

Correspondencia a:

Carlos Osorio A.

gonosorio@med.uchile.c 
efluvio vicioso, emanado de un ser viviente enfermo, $i$ que ocasiona en otro idéntica enfermedad, transmitiéndose el principio contajioso por el conducto del aire, o por el contacto de aquellas cosas que se ha relacionado entre ambos de un modo íntimo e inmediato"s. En la siguiente década se difundieron con rapidez y fuerza los nuevos conocimientos traídos de Europa. Se debe recordar que justamente durante este período, como se mencionará en detalle más abajo, fueron becados a Europa varios médicos que regresaron a Chile con los conocimientos y prácticas médicas del viejo continente. Algunos médicos de la antigua Escuela de Medicina de calle San Francisco comenzaron a utilizar el término de "bacterios" aplicado a ciertos infusorios como probables agentes etiológicos de viruela, específicamente mencionan el denominado Bacterium termo de Müller y el Bacterium bacillus de Vasteur $[\text { sic }]^{6}$. Incluso algunos declaran conocer en detalle los trabajos contemporáneos de Pasteur sobre generación espontánea ${ }^{7}$. La moderna teoría de los gérmenes, paradigma que sustituiría finalmente a la teoría multicausalmiasmática predominaba ya en la década de 1880 . A modo de ejemplo se citarán dos párrafos de la memoria del alumno de medicina don Manuel Gundelach para optar al grado de licenciado en la Facultad de Medicina titulada "Algunos apuntes sobre la pyohemia" que en 1882 expresaba lo siguiente: "He leído, señores, los estudios de Pasteur sobre los fermentos, que serán el objeto de la primera parte de estos lijeros apuntes, considerando la pyohemia bajo el importante papel que desempeñan los microbios en las enfermedades infecciosas $i$ de qué manera estos jérmenes llegan a obrar en el desarrollo de la pyohemia". En otro párrafo en que explica lo que es un fermento expresa: "Cada uno de ellos (los fermentos) tiene vida propia y se necesita gran trabajo y paciencia para poder aislarlos. De este modo se hacen las esperiencias, ya sea inyectando o inoculando tal o cual fermento que produce precisamente tal o cual enfermedad". Este trabajo y otros semejantes de la época, indican que claramente a dicha fecha el nuevo paradigma que consideraba a los gérmenes o microbios como los agentes etiológicos responsables de las enfermedades infecciosas era ya un hecho ampliamente reconocido, al menos, en el ámbito académico ${ }^{9}$.

\section{Primeros becados a Europa}

Como se adelantó en la sección anterior, la difusión y consolidación definitiva de la nueva teoría de los gérmenes sólo vendría a producirse, luego de un hito fundamental en la historia de la medicina y ciencias biológicas nacionales: el envío en 1874-1875 de los cinco primeros médicos becados chilenos a Europa por el Dr. José Joaquín Aguirre (Decano de la Facultad de Medicina de la Universidad de
Chile entre 1867-1877 y luego entre 1886-1889; rector de la Universidad de Chile entre 1889-1893). Los jóvenes elegidos por el destino para cambiar los rumbos de la medicina nacional fueron los médicos Francisco Puelma Tupper (Anatomía Patológica), Manuel Barros Borgoño (Cirugía), Vicente Izquierdo Sanfuentes (Histología), Carlos Sazié Heredia (Enfermedades Mentales) y Máximo Cienfuegos Sánchez (Oftalmología) ${ }^{10}$. Estos jóvenes brillantes eran en ese momento estudiantes de medicina de la antigua Escuela de calle San Francisco y su esfuerzo, perseverancia y tenacidad los transformaría con el tiempo en los líderes naturales de una revolución médica que estaba por comenzar en dicha escuela y que se plasmaría materialmente en la construcción de la nueva Escuela de Medicina ubicada en la Cañadilla. Como si hubiese sido necesario, para que esta nueva generación médica germinara, el hecho que se destruyera los cimientos de la antigua Escuela para reemplazarlos por una nueva estructura material y espiritual. Es pertinente recordar aquí la conocida frase atribuida al insigne físico Max Planck que dice que: una nueva verdad no se impone porque convenza a sus oponentes sino porque éstos desaparecen paulatinamente y son reemplazados por una nueva generación. En este caso, sin embargo, se debe destacar que la antigua generación avizoró los cambios que era necesario realizar, diseñó el mecanismo y participó activamente en el proceso de renovación.

\section{La primera Cátedra de Bacteriología en Chile}

Como se puede observar, no hubo becados de Bacteriología entre los primeros jóvenes enviados a Europa, debiendo esperar esta disciplina casi dos décadas más para iniciar su exitosa historia y recorrido en Chile. Sin embargo, la llegada de los primeros becados, impregnados de las nuevas ideas científicas prevalentes en Europa, fue un catalizador directo para la creación de la Cátedra de Bacteriología y otras Cátedras de especialidades clínicas que no existían en el país. Por ejemplo, existen trabajos publicados que indican que los Drs. Francisco Puelma Tupper (Anatomía Patológica) y Vicente Izquierdo (Histología), ambos usuarios frecuentes del microscopio en sus respectivas disciplinas, también trabajaron y fomentaron los primeros estudios microbiológicos ${ }^{11-14}$. Estos estudios incipientes y el fuerte liderazgo y visión de estos maestros pronto dio sus primeros frutos, pues uno de los alumnos y ayudante del laboratorio del Dr. Puelma Tupper fue elegido y enviado por el gobierno a Europa a formarse en la nueva ciencia. Este joven brillante fue el Dr. Alejandro del Río Soto Aguilar (1867-1939) titulado como médico en 1889 y becado a Alemania en 1892 (Figura 1). Permaneció cuatro años en dicho país (1892-1895), formándose 


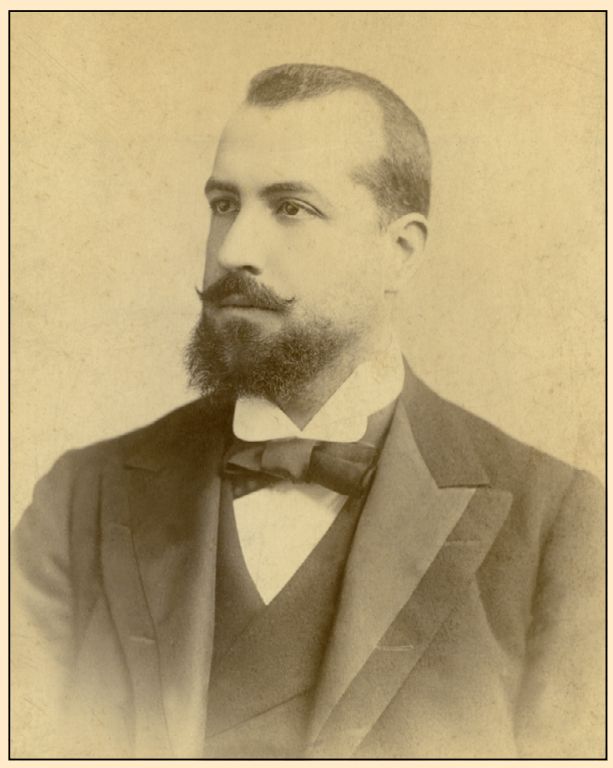

Figura 1. Dr. Alejandro del Río Soto Aguilar (1867-1939).

en los principales centros de microbiología germanos de la época (laboratorios de los célebres bacteriólogos Max von Pettenkoffer, Robert Koch y Karl Joseph Eberth). De vuelta en Chile fue nombrado Profesor Titular de la recién creada Cátedra de Bacteriología (1895). El Dr. del Río mantuvo este cargo por un corto período (1895-1901), pues rápidamente su interés se centró en mejorar aspectos relacionados con el estado deplorable de la Salud Pública e Higiene imperantes en nuestro país en dicha época (red de alcantarillado, desinfectorio público, red de atención de urgencia, etc.), motivo que lo llevó a alejarse tempranamente de su Cátedra ${ }^{15}$.

$\mathrm{Su}$ sucesor inmediato fue el Dr. Mamerto Cádiz Calvo (1863-1929) (Figura 2). Con seguridad podemos afirmar que sus maestros de Histología y Anatomía Patológica en la Facultad de Medicina también fueron los Drs. Izquierdo y Puelma Tupper, respectivamente. El profesor Cádiz se tituló de médico en 1889, junto al Dr. Alejandro del Río, y posteriormente fue becado por el gobierno a Europa entre 1897-1899, trabajando en el Instituto Pasteur (laboratorios de Émile Roux e Ilya Metchnikoff) y el Instituto Koch de Berlín. El Dr. Cádiz tiene el mérito de haber sido el maestro que consolidó la enseñanza de la Bacteriología en Chile ${ }^{16}$. La Cáterda del Dr. Cádiz, se dictaba en el pabellón de sueroterapia del antiguo edificio del Instituto de Higiene (1892-1924) en calle Borgoño 1470 junto al río Mapocho.

El Dr. Cádiz durante su larga y destacada carrera académica de casi tres décadas como el maestro indiscutido de la Bacteriología (entre 1901-1927) formó a innumerables discípulos, entre los que podemos destacar

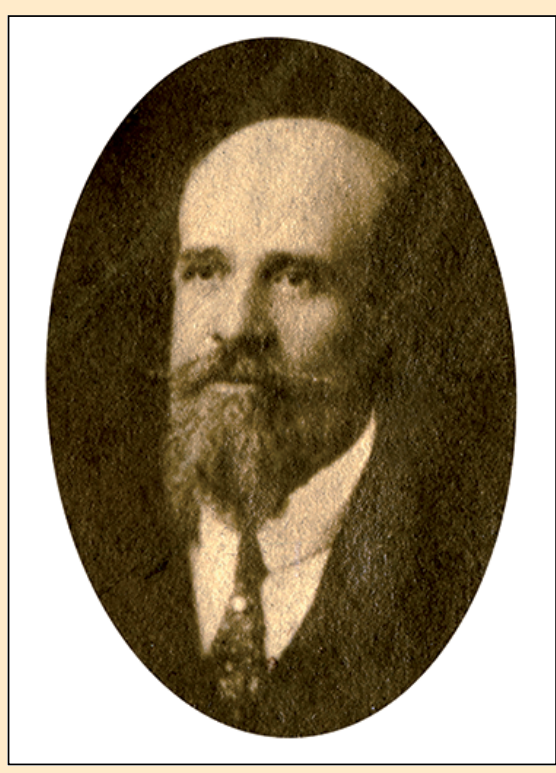

Figura 2. Dr. Mamerto Cádiz Calvo (1863-1929).

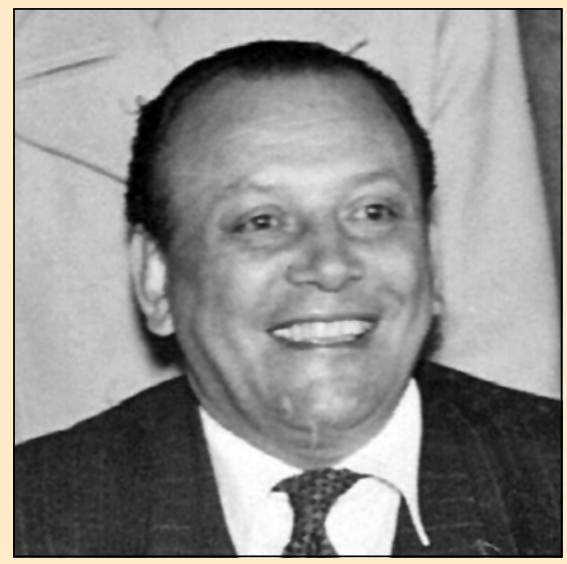

Figura 3. Dr. Hugo Vaccaro Cosovich (1902-1975).

a su sucesor directo en dicha Cátedra Ordinaria o Titular, el Dr. Enrique Onetto Aguilar que dirigió la Cátedra entre 1928-1931 ${ }^{17}$. El Dr. Onetto se tituló de médico en 1923 con la tesis denominada "El líquido céfalo-raquídeo en la sífilis" y dirigió la Cátedra por un período muy breve pues renunció a su cargo durante la crisis política de 1931, sucediéndole otro joven microbiólogo formado bajo la dirección del Dr. Cádiz, el Dr. Hugo Vaccaro Kosovich (Profesor Cátedra Titular entre 1931-1970) (Figura 3) ${ }^{18}$. El Dr. Vaccaro se había titulado como médico en 1928 con la tesis "Complicaciones pulmonares en cirugía gástrica y vacunación preventiva" y luego trabajó en el Instituto Sanitas (dirigido por el Dr. Cádiz). En dicho 
Figura 4. Dr. Eugenio Suárez Herreros (1899-1977).

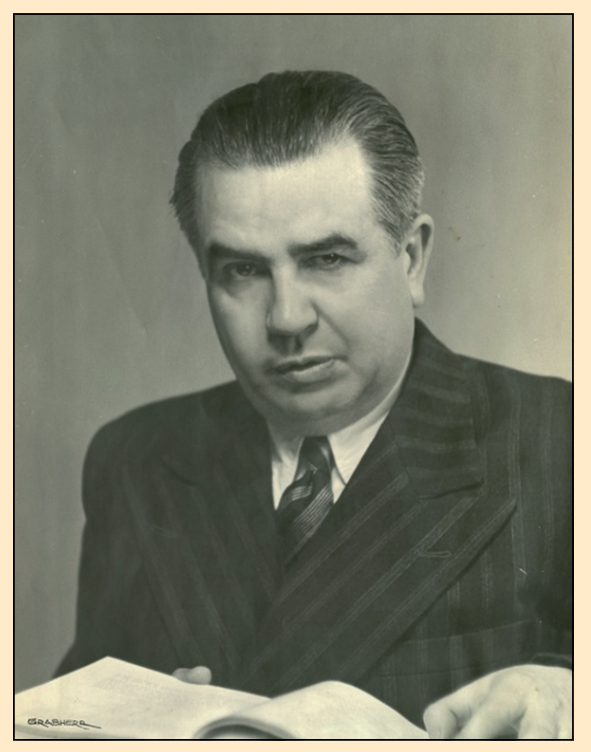

Figura 5. Dr. Eduardo Dussert Jolland (19021973).

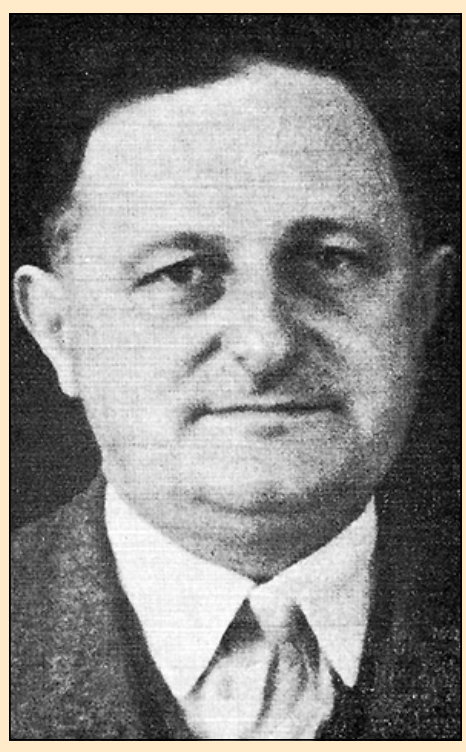

Instituto, fundado en 1920, trabajó el destacado investigador francés Eugène Wollman (1883-1943), quien trajo a Chile las primeras técnicas para trabajar con bacteriófagos y junto a quien el Dr. Vaccaro profundizó sus conocimientos. El Dr. Vaccaro dirigió su Cátedra Titular hasta 1970 (aquel año se trasladó la Cátedra Titular de Bacteriología desde su antiguo edificio de Borgoño 1470 al nuevo edificio de la Facultad de Medicina en avenida Independencia 1027), siendo sucedido por su principal discípulo el Dr. Leonardo Paredes Pedreros. Paralelamente a la Cátedra Titular dirigida por el Dr. Vaccaro en la Facultad de Medicina se formó una segunda Cátedra Extraordinaria de Bacteriología e Inmunología localizada primeramente en el Instituto Bacteriológico de Chile (1929-1980) (localizado en dicha época en calle Borgoño 1470, al poniente de la avenida Independencia y luego trasladada en 1950 junto al Instituto a la comuna de Ñuñoa en calle Maratón 1000), dirigida inicialmente por el Dr. Eugenio Suárez Herreros (Profesor Cátedra Extraordinaria entre 1929-1950) y luego por el Dr. Eduardo Dussert Jolland (Profesor Cátedra Extraordinaria entre 1950-1973) (Figuras 4 y 5, respectivamente) ${ }^{19-20}$. El Dr. Suárez Herreros se había titulado en 1922 con la tesis “Acción farmacodinámica y farmacoterápica de los yódicos" y el Dr. Dussert en 1927 con la tesis "Reacción de fijación del complemento en la tuberculosis". El Dr. Dussert falleció trágicamente en un accidente vial en Santiago en 1973 siendo sucedido por la Dra. Beatriz Lynch Flanagan. Todos estos pioneros de la Microbiología en Chile se formaron inicialmente en la disciplina dentro de la Cátedra dirigida por el Dr. Mamerto Cádiz en la Escuela de Medicina de la Cañadilla de la Universidad de Chile ${ }^{21-23}$.

\section{Nuevas Cátedras de Bacteriología en Chile}

Desde la Cátedra del Dr. Cádiz algunos de sus discípulos emigraron y difundieron la semilla microbiológica en los nuevos centros de educación superior que se habían creado en el país, esto es, la Universidad Católica de Chile (fundada en 1889) y la Universidad de Concepción (1929). El primer catedrático de Bacteriología en la Escuela Médica de la Universidad Católica fue el Dr. Enrique Dávila Húmeres ${ }^{24}$. El Dr. Dávila nació en Santiago en 1892 y estudió en el Colegio San Ignacio. Sus estudios médicos los realizó en la Escuela de Medicina de la Universidad de Chile, titulándose en 1917 con la tesis "Reumatismo articular agudo". Fue becado luego por el gobierno para estudiar Bacteriología en el Instituto Pasteur (1921) y luego se desempeñó como médico del Laboratorio Central del Hospital San Vicente de Paul y como profesor de una segunda Cátedra Extraordinaria de Bacteriología en la Universidad de Chile en 1929. Finalmente el Dr. Dávila fue nombrado Profesor Titular de la Cátedra de Bacteriología en la Escuela de Medicina de la Universidad Católica de Chile (Escuela fundada en 1929), cargo que desempeñó entre 1940-1945, iniciándose así la enseñanza de esta disciplina en dicha Universidad. Su sucesor en la Cátedra fue el Dr. Felipe González Antolín ${ }^{24-25}$.

En Concepción la Bacteriología inició sus actividades en 1920 con el Dr. Osvaldo Figueroa Domínguez. El Dr. Figueroa se tituló de médico en la Universidad de Chile en 1918 con la tesis "El citodiagnóstico en las afecciones gástricas”. En 1920 inició la enseñanza de la Bacteriología en la Escuela Dental de la Universidad de Concepción (fundada en 1919) y luego en la Escuela de Medicina de 
dicha Universidad (fundada en 1924). Su sucesor en la Cátedra fue el Dr. Liborio Moraga ${ }^{24-25}$.

\section{Conclusiones}

Esta breve reseña histórica sobre los orígenes de la enseñanza de la Bacteriología en Chile, muestra que el centro de enseñanza original de esta disciplina en Chile fue la Cátedra creada por el Dr. Alejandro del Río y luego consolidada por el Dr. Mamerto Cádiz. De una u otra manera, la gran mayoría de los microbiólogos formados en Chile durante el siglo veinte se vinculan con una de las Cátedras mencionadas en este trabajo, algunos directamente y otros, a través de centros secundarios que emergieron paulatinamente de los originales (Figura 6). La Cátedra madre del Dr. del Río surgió y tuvo su desarrollo en el antiguo edificio de la Escuela de Medicina de la Cañadilla y su hospital clínico anexo llamado hospital San Vicente de $\mathrm{Paul}^{26}$. Se debe recordar que dicho hospital junto a su hermano gemelo, el hospital del Salvador, surgió como un lazareto para enfrentar las enfermedades infecciosas epidémicas que azotaban periódicamente a Chile en dicha época (e.g. viruela, cólera, escarlatina, etc.). El destino quiso que precisamente este lazareto, donde era habitual la muerte causada por agentes infecciosos, fuera donde la nueva ciencia microbiológica germinara e iniciara su largo y fecundo recorrido en la medicina nacional. El hospital San Vicente estaba localizado en el antiguo barrio de la Chimba de la ciudad de Santiago, en aquellos años una zona semi-rural ubicada al costado norte del río Mapocho, donde hoy se emplaza el Hospital Clínico José Joaquín Aguirre y el campus norte de la Facultad de Medicina de la Universidad de Chile ${ }^{21,27}$.

Agradecimientos: Quisiera agradecer especialmente al Museo de Historia de la Medicina de la Facultad de Medicina de la Universidad de Chile por facilitarme imágenes digitales de distintos profesores y al Sr. José Fernández Maturana de la sección Revistas de la Biblioteca de la Facultad de Medicina de la Universidad de Chile por su ayuda en la búsqueda de documentos utilizados para este estudio.

\section{Resumen}

La primera Cátedra de Microbiología fue creada en la Escuela de Medicina de la Cañadilla de la Universidad de Chile en 1892. Su primer profesor fue el Dr. Alejandro del Río Soto Aguilar. Por casi tres décadas esta Escuela fue el único centro formador de microbiólogos para la nación, destacándose entre ellos los padres fundadores de las nuevas Cátedras de Microbiología de la Escuela de Medicina de la Universidad Católica y la Universidad de Concepción.

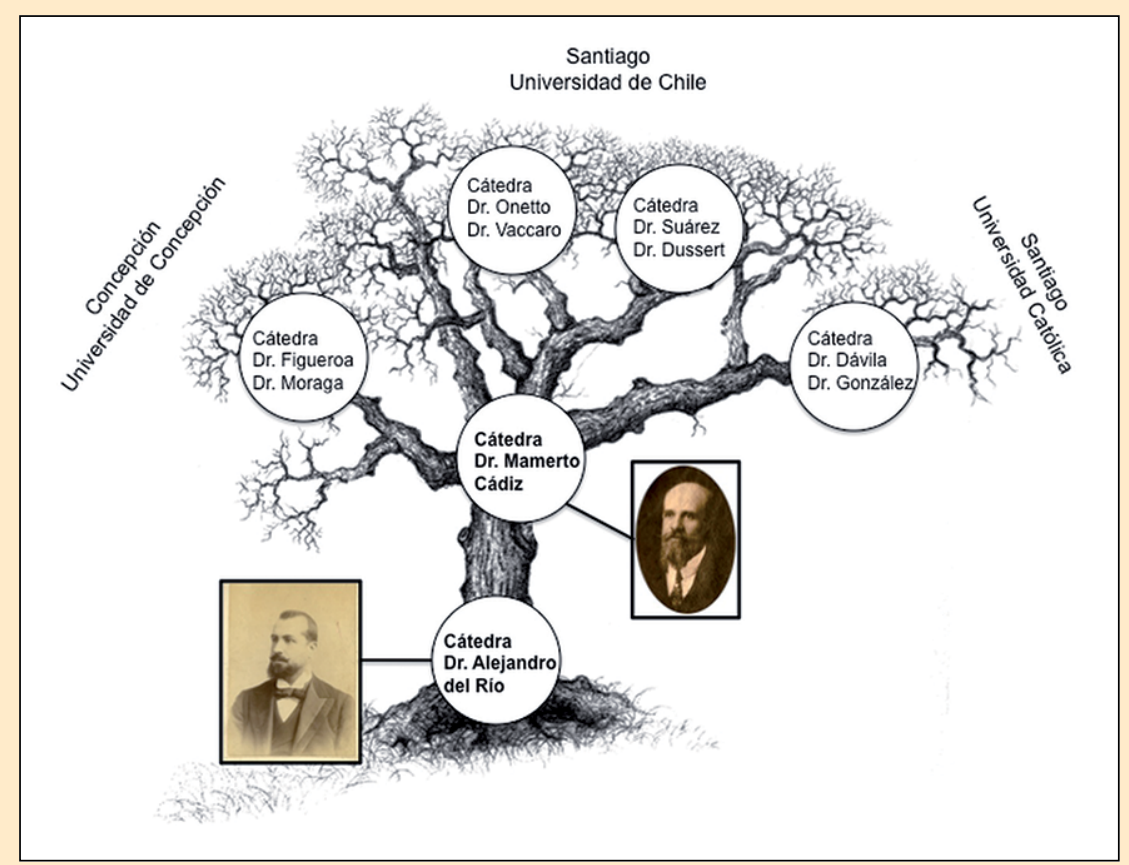

Figura 6. Árbol genealógico de la enseñanza microbiológica en Chile.

\section{Referencias bibliográficas}

1.- Bulloch W. The History of Microbiology. First Edition. Oxford University Press. London, Great Britain, 1938.

2.- Piderit T. Observaciones sobre el Cólera. AUCH 1852; 9: 466-73.

3.- Osorio C G. Sobre agentes infecciosos, zoofitos, animálculos e infusorios. Rev Chil Infectol 2007; 24: 171-4.

4.- Saldías V. Causa de las epidemias. AUCH 1865; 27: 351-73.

5.- Carmona M A. Epidemias. Informe médico-legal epidemia viruela Valparaíso. AUCH 1865; 27: 373-84.

6.- O'Rian P. Revista de la epidemia de viruela de 1872 . Rev Med Chile 1872; 1: 274.

7.- Candia P. Jeneración espontánea. Rev Med Chile 1874; 3 : 105-13.

8.- Gundelach M. Algunos apuntes sobre pyohemia. AUCH 1882; 61: 222-48.

9.- Kuhn T S. La estructura de las revoluciones científicas. Fondo de Cultura Económica de España, 2005.

10.- Costa-Casaretto C. Los primeros becarios chilenos en Europa (1874); Rev Med Chile 107: 432-7.

11.- Del Río A. Contribución al estudio de la etiología y anatomía patológica de los abscesos del hígado. Rev Med Chile 1889; 18: 249-305.

12.- Del Río A. El micro-organismo de la disentería. Rev Med Chile 1888; 17: 267-9.

13.- Izquierdo V. El Bacillus Kochii i la tuberculosis. Rev Med Chile 1883; 12: 39-49.

14.- Izquierdo V. El microbio de la blenorrajia. Rev Med Chile 1884; 13: 16-21.

15.- Couchot JM. Dr. Alejandro del Río. Rev Med Chile 1971; 99: 892-6. 
16.- González Ginouves I. El Dr. Mamerto Cádiz. Rev Med Chile 1983; 111: 1307-10.

17.- Boletín Instituto Bacteriológico de Chile. Enrique Onetto Aguilar. 1972. Volumen XIV: 45.

18.- Paredes L. Semblanza Dr. Hugo Vaccaro Cosovich. Bol Chil Parasitol 30: 46-7.

19.- Boletín Instituto Bacteriológico de Chile. Eugenio Suárez Herreros. 1977. Volumen XIX: 55-6.

20.- Boletín Instituto Bacteriológico de Chile. Eduardo Dussert Jolland. 1973. Volumen XV: 30-1.

21.- Osorio CG. Escuela Medicina de la Cañadilla. Rev Med Chile 2013; 11: 1484-8.

22.- Sierra L. Cien años de la enseñanza de la medicina en Chile.
An Fac Biol Med 1934; 1: 1-134.

23.- Cruz-Coke R. Historia de la Medicina Chilena. Editorial Andrés Bello, primera Edición, Santiago de Chile, 1995.

24.- Monge G. Diccionario biográfico médico mundial. Barcelona, España, 1958.

25.- Rodríguez M. La microbiología en Chile: su desarrollo a la luz de un siglo de existencia. Rev Med Chile 1992; 120 : 463-70.

26.- Núñez H, Osorio C G. Arqueología del Hospital San Vicente de Paul. Rev Med Chile 2007; 135: 264-9.

27.- Rosales J. La Cañadilla de Santiago: su Historia y sus Tradiciones 1541-1887. Sangría Editora, Santiago, Chile, 2010. 